\title{
Colecionadores da beleza: a singularidade natural das borboletas em perspectiva histórica e multidisciplinar
}

\section{Collectors of beauty: the natural singularity of butterflies from a historical and multidisciplinary perspective}

\author{
Nelson Aprobato Filho \\ Pós-doutor em História/Universidade de São Paulo. \\ São Paulo - SP - Brasil \\ aprobato@usp.br
}

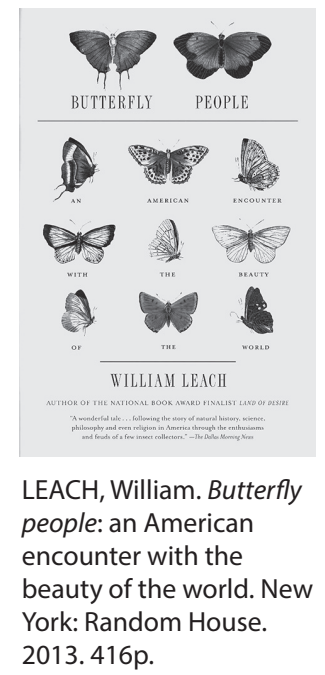

T $m$ 1875, o norte-americano Herman Strecker recebia, em sua Ecasa, uma rara borboleta brasileira que fora comprada, por um amigo, no Rio de Janeiro. Strecker o considerou o mais notável lepidóptero conhecido e o nomeou Eudaemonia jehovah, escolha que gerou grande discussão sobre a conveniência de se colocar um nome religioso em um animal. Strecker defendeu sua opção afirmando que não via problema em usar o nome do Criador em uma de suas mais interessantes criaturas: a singular borboleta brasileira.

Strecker, que nasceu e viveu nos EUA entre 1836 e 1901, dividia sua rotina de trabalho em duas atividades. Durante o dia, para sobreviver, dedicava-se à escultura de peças em mármore. Quando a noite caía, com a obssessão de um colecionador fanático, consumia horas entre suas borboletas. Era na calada da noite que fazia o que mais gostava: empalhar, identificar, classificar e descrever os insetos; ler sobre lepidópteros; e manter atualizada sua copiosa correspondência. Como uma mariposa em torno da luz, o único foco de seu mundo noturno era aquele que incidia sobre sua imensa coleção. Poucos anos após começá-la, possuía mais de trinta mil espécies. Por volta de 1895, o quarto andar de sua casa era ocupado com sessenta mil duplicatas destinadas à venda. Em 1900 sua coleção contava com duzentas mil borboletas. Para se ter uma ideia da representatividade do acervo, basta lembrar que uma das maiores coleções públicas existentes no Brasil na atualidade, que se encontra no Museu de Zoologia da Universidade de São Paulo, conta com 290 mil exemplares. Em 1908, pouco depois do falecimento de Strecker, o conjunto contendo sua coleção de lepidópteros e sessenta mil itens entre livros e correspondência foi vendido para o Field Museum of Natural History de Chicago. O carregamento ultrapassou sete toneladas. Strecker fez parte de um grupo de colecionadores norte-americanos que influenciou o início e o desenvolvimento da lepidopterologia nos EUA. 
O responsável por reconstruir essa história, espécie de saga na busca por borboletas, foi William Leach (2013), historiador da Columbia University, no livro Butterfly people: an American encounter with the beauty of the world. $\mathrm{O}$ argumento principal do autor foi analisar como os norte-americanos despertaram, em meados do século XIX, para a beleza e importância das borboletas e, com o passar dos anos, de que forma esse deslumbramento foi perdendo espaço para outras concepções de beleza resultantes, principalmente, das descobertas da revolução científico-tecnológica a partir de 1870. Nesse percurso interpretativo Leach ressaltou o impacto e o significado das transformações tecnológicas tanto para o mundo natural como para a cultura norte-americana.

Para elaborar a investigação, o autor recorreu a uma extensa seleção de fontes primárias produzidas no universo da ciência que estuda as borboletas, como cartas, diários, catálogos etc. Além disso, para a construção dos capítulos e de suas argumentações, colocou essas fontes em diálogo com atualizada bibliografia sobre o tema.

O estudo de Leach foi construído a partir de biografias de um grupo de colecionadores de borboletas. Além da de Strecker, abordou a vida de Samuel Scudder, Henry Edwards, Augustus Radcliffe Grote e William Henry Edwards, os founding fathers da lepidopterologia norte-americana. Partindo desses representativos nomes, criou uma complexa rede analítica das relações interpessoais entre eles, e deles com inúmeros outros colecionadores ao redor do mundo. Por outro lado, por meio das atividades desses cinco personagens, tece uma teia na qual vai reconstruindo a história da lepidopterologia. Essa rede e essa teia interpenetram-se nas duas partes em que o livro foi dividido - "Encounters with the butterflies of America" e "Encounters with the butterflies of the world" - e em cada um dos oito capítulos que retomam, sob um aspecto específico, a contribuição histórica e científica desses colecionadores e de suas coleções. Enriquecendo a edição, há quatro cadernos com imagens de algumas das borboletas apresentadas no livro.

Possivelmente a obra não teria a importância que tem se Leach tivesse ficado preso apenas aos seus protagonistas. Ao contrário disso, e essa é uma das maiores contribuições do livro, o autor desenvolve as biografias entrelaçando-as ao conturbado contexto histórico do século XIX, com destaque para os aspectos político-econômicos e, principalmente, científicotecnológicos. É dentro desse contexto que Leach analisa a história da lepidopterologia norteamericana e discute de que forma essa ciência influenciou outros campos do conhecimento, abrindo uma promissora perspectiva multidisciplinar.

$\mathrm{Na}$ área científica, por exemplo, fornece ilações sobre a importância do estudo das borboletas para comprovar ou detratar a Teoria da Evolução de Charles Darwin. Não somente Darwin, mas também Henry Bates e Alfred Russel Wallace pesquisaram os lepidópteros.

Não menos instigantes são as análises sobre o comércio de borboletas. Enquanto Londres foi o polo mundial para tal empreendimento, com comerciantes como Alfred Wailly, na Alemanha destacou-se Otto Staudinger. A atividade de Staudinger era tão lucrativa que, em 1884, ele construiu em Dresden uma moradia de três andares para, nos dois inferiores, armazenar sua coleção destinada ao mercado. Para manter o monopólio tinha um exército de coletores. Na década de 1870 Heinrich Ribbe, para citar apenas um de seus contratados, enviou para Staudinger dez mil borboletas capturadas no Panamá e no Peru. Os EUA também tiveram presença marcante nesse mercado internacional, e, 
nesse mesmo período, Herbert Smith e Daisy Smith coletaram, na região amazônica, 15 mil exemplares, de 1.800 espécies. Levantamentos e análises como esses podem fornecer elementos para pesquisas sobre a circulação e o consumo internacional de fauna silvestre, inclusive brasileira.

Para além dos objetivos do autor, Butterfly people apresenta, entre outros importantes fios analíticos, elementos para pensar a história ambiental. Permite que saibamos, por exemplo, que um dos fatores que impulsionaram a lepidopterologia norte-americana foi a destruição da natureza. Os fazendeiros, ao desmatar grandes áreas, supriram os colecionadores com verdadeiro manancial de borboletas. O comércio indiscriminado e as consequências da revolução científico-tecnológica também estão entre os fatores principais para a extinção de espécies após 1900.

Contudo, Leach aponta que foi nesse período que uma nova consciência, que defendia a preservação das borboletas, começa a tomar forma. No capítulo em que analisa a arte da ilustração na lepidopterologia - técnica que utilizou, durante o século XIX, milhares de exemplares mortos como modelos -, o autor cita o trabalho de Gebe Stratton-Porter, escritora norte-americana de livros infantojuvenis. Além de escritora, era amante da fotografia. Para ela, o processo fotográfico poderia salvar do extermínio inúmeras espécies. Em um de seus livros, lançado em 1912, Stratton-Porter escreveu: "A diferença entre essas perfeitas criaturas vivas e os enrugados e perfurados objetos que ilustram muitos livros de borboletas que eu possuo, é a diferença entre a vida abundante e a morte repulsiva" (citada em Leach, 2013, p.241).

A profundidade, multiplicidade e profusão de temas, abordagens e dados históricos apresentados no livro e sumarizados acima o transformam em fonte de referência e reflexão que extrapola a área da lepidopterologia. Nesse sentido, Buterffly people cumpre destacado papel multidisciplinar e é um estudo que fornece inestimáveis contribuições para áreas que vão da história da ciência e do meio ambiente à história dos EUA e das relações entre o homem e os animais, da história natural à história da biologia e da zoologia, passando pela história da ecologia, da economia, da tecnologia e das relações internacionais.

\section{REFERÊNCIA}

LEACH, William.

Butterfly people: an American encounter with the beauty of the world. New York: Random House.

2013.

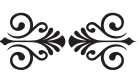

